\title{
Determining Interval Time of Maintenance in Bosowa Cement Indonesia using Reliability Method
}

\author{
Muhammad Arsyad Suyuti ${ }^{1, a}$ and Rusdi Nur ${ }^{1,2, b}$ \\ ${ }^{1}$ Mechanical Engineering Department, Politeknik Negeri Ujung Pandang, \\ Jl. Perintis Kemerdekaan Km. 10, Makassar, 90245, Indonesia \\ ${ }^{2}$ Centre for Manufacturing and Materials, Politeknik Negeri Ujung Pandang, \\ Jl. Perintis Kemerdekaan Km. 10, Makassar, 90245, Indonesia \\ a muhammadarsyadsuyuti@poliupg.ac.id \\ b rusdinur@poliupg.ac.id
}

\begin{abstract}
Maintenance for machining and production facility is an important aspect to ensure a smooth production process. During this time, it was performed regular maintenance based on technical advice from supplier's engines which just shows things in general without considering the actual operating conditions. This paper aims to plan the maintenance strategies for the Finish Mill unit based on reliability analysis by considering the target system reliability and cost of improving reliability. The data distribution obtained the most appropriate distribution. Based on the data obtained distribution parameters, then the function of the reliability of each part can be determined so that the value of the reliability of each part and the overall system for a specific time period can be calculated. The results showed that the failure or breakdown Mill Finish Unit was majority caused by the part of 561.BM1, 531.WF1, 531.BC6, 531.BC2, 531.BC1, 561.SR1 and 531.BC3. it means that need to focus o the reliability analysis to allocate their parts.
\end{abstract}

Keywords—reliability; maintenance; downtime

\section{Introduction}

Reliability has become critical and continues to increase along with the development of rapid technological innovation. It deals with the aim to produce goods of high quality and high reliable design. There are many researchers who have been investigating the complex phenomena in fact statistically systems to improve their reliability.

Reliability is defined as the attribute of a component or system to perform a required function for a given period of time when used under stated operating conditions [1]. To use this concept in an operational sense, the attribute should be measured by quantitative metrics. These metrics are referred to as reliability metrics. Traditionally, reliability metrics are defined based on probability theory, such as the reliability (interpreted as a probability) and the mean time to failure (MTTF). Measuring reliability refers to determining the values of the reliability metrics. Some researchers are using alternative model and new theory of reliability with regard to non-probability, i.e. Onisawa [2], Cappelle and Kerre [3], Cai [4], Cremona and Gao [5], Utkin and Gurov [6], etc.

This paper presents the optimization of maintenance interval time on the unit Finish Mill of PT. Bosowa Cement of Indonesia using reliability approach.

\section{Methodology}

\section{A. Case Study}

This paper studies the capabilities and maintenance of equipment in a factory. As a case study, this study was focused on the condition of equipment on the unit Finish Mill of PT. Bosowa Cement of Indonesia.

The observation was conducted to perform data retrieval of machine downtime for each part in the Maintenance Department during the three months. The variable was identified as below:

- Finish mill unit consists of 100 parts and only 31 parts have data downtime.

- Details of downtime data was in the form of daily production operation data (log sheet).

- Pareto analysis is performed to determine cost data preventative maintenance and financing costs due to 
damage to the part failure causes major damage to the frequency of $80 \%$ of the total cumulative damage frequency.

- Losses due to damage (loss of production).

- All external factors that are not expected to be negligible.

\section{B. Data Analysis}

The observation data were analyzed using WeibullPlus 4.0 software for the analysis of reliability with the following steps:

- Finish mill unit consists of 100 parts and only 31 parts have data downtime.

- Downtime data of production operations (log sheet) was converted into the data of Time between Failures (TBF).

- Estimation of TBF distribution was using Weibull-Plus 4.0 software with Rank Regression method, then compared by the Goodness of Fit, Fit Plot, and Likelihood Function Value.
- Furthermore, the probability distribution is most appropriate for the data $\mathrm{TBF}$, and then it will get reliability function, Failure rate, and MTBF for each part.

- Lastly, the reliability of analysis results can be used to determine maintenance strategies in achieving planned system reliability.

\section{Result and Discussion}

\section{A. Pareto Analysis}

The result of Pareto analysis based on the data TBF for two years of production indicate that the failure was caused by the parts as shown in Figure 1.

Furthermore, the reliability analysis of maintenance interval was focused on the major part failure (over 80.6\%), namely: 561.BM1, 531.WF1, 531.BC6, 531.BC2, 531.BC1, 561.SR1 and 531.BC3. In order to perform with modelling of the reliability, parts which have a low percentage of failure frequency can be assumed to have $100 \%$ reliability.

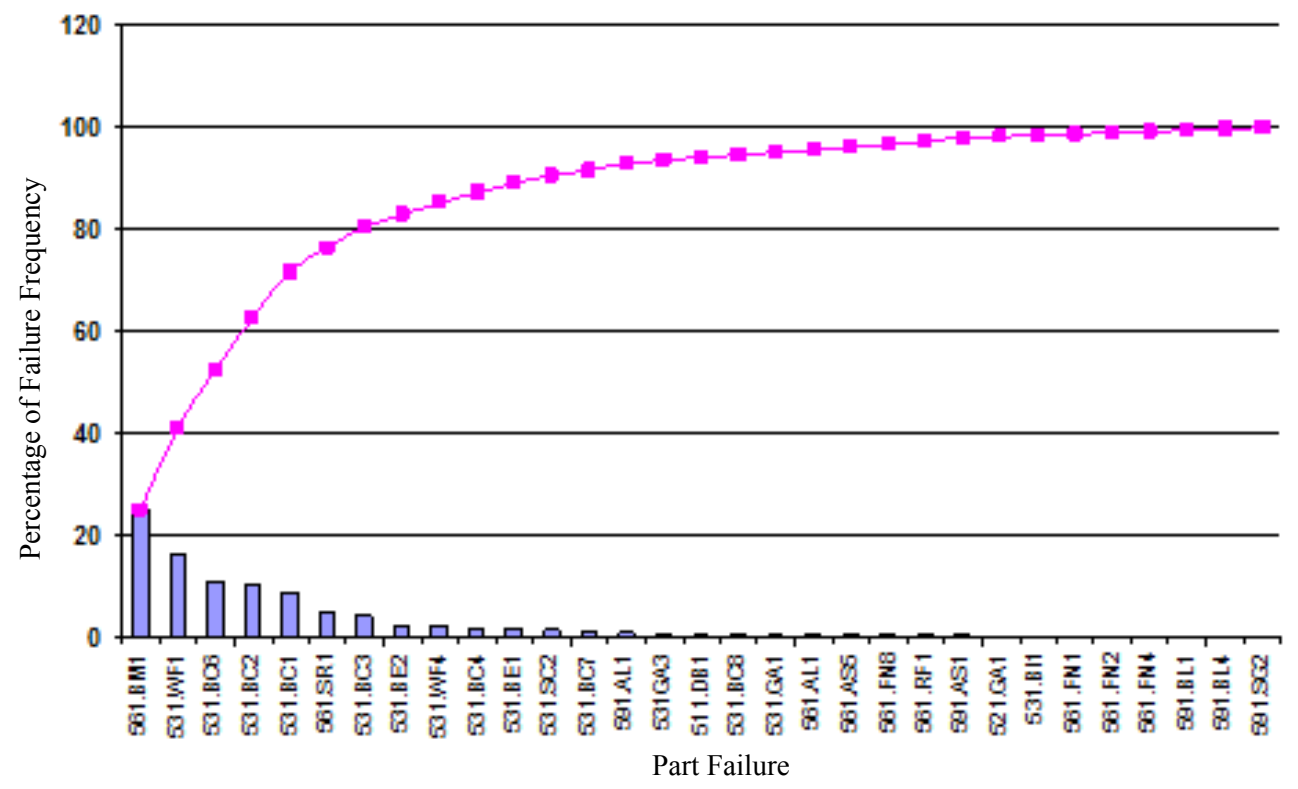

Figure 1. Pareto diagram for the failure frequency of the Finish Mill 


\section{B. Analysis of Selecting Distribution}

The statistical distribution of TBF for each main failure in Finish Mill Unit and its parameters are shown in Table 1.

Table 1. Distribution of Data TBF

\begin{tabular}{|c|c|c|l|}
\hline No & Part & Distribution & \multicolumn{1}{|c|}{ Parameter } \\
\hline 1 & $561 . \mathrm{BM} 1$ & Lognormal & $\mathrm{t}_{0}=4.278, \mathrm{~s}=1.323$ \\
\hline 2 & $531 . \mathrm{WF} 1$ & Lognormal & $\mathrm{t}_{0}=4.628, \mathrm{~s}=1.381$ \\
\hline 3 & $531 . \mathrm{BC} 6$ & Lognormal & $\mathrm{t}_{0}=4.788, \mathrm{~s}=1.590$ \\
\hline 4 & $531 . \mathrm{BC} 2$ & Weibull & $\begin{array}{l}\beta=0.623, \eta=231.856, \\
\gamma=10.082\end{array}$ \\
\hline 5 & $531 . \mathrm{BC} 1$ & Weibull & $\begin{array}{l}\beta=0.723, \eta=327.387, \\
\gamma=0.710\end{array}$ \\
\hline 6 & $561 . \mathrm{SR} 1$ & Lognormal & $\mathrm{t}_{0}=5.434, \mathrm{~s}=1.684$ \\
\hline 7 & $531 . \mathrm{BC} 3$ & Weibull & $\begin{array}{l}\beta=0.555, \eta=791.862, \\
\gamma=0.161\end{array}$ \\
\hline
\end{tabular}

\section{Analysis of Failure Rate and MTBF}

MTBF analysis was required as the consideration to determine the maintenance interval for the reliability analysis, which used data TBF. The result of MTBF analysis can be shown in Table 2 .

Table 2. Failure Rate, MTBF Value and Reliability of Parts

\begin{tabular}{|c|c|c|c|c|}
\hline No & Part & Failure Rate & MTBF & R (\%) \\
\hline 1 & $561 . B M 1$ & Decrease & 173.053 & 25.41 \\
\hline 2 & 531. WF1 & Decrease & 265.803 & 24.49 \\
\hline 3 & 531. BC6 & Decrease & 242.738 & 21.33 \\
\hline 4 & $531 . B C 2$ & Decrease & 341.548 & 28.67 \\
\hline 5 & $531 . B C 1$ & Decrease & 411.517 & 30.78 \\
\hline 6 & 561. SR1 & Decrease & 230.391 & 49.85 \\
\hline 7 & $531 . B C 3$ & Decrease & 402.145 & 50.34 \\
\hline
\end{tabular}

Table 2 shows that all parts for main cause of the failure have curve trend decreased. This trend included in the category of burn-in period. This failure can be caused by unskilled operators, the unfixed installation, low quality control that needed some further adjustments. This table also shows that the useful life for all parts of the main causes of failure in Finish Mill unit was 173 hours until 411.5172 hours. The maintenance system was appropriate, break down can be avoided. Data MTBF can be used as consideration for determining the maintenance interval. Overall component has actual MTBF value is smaller than the inspection scheduled. This can cause the reliability of each component is very low due to the frequent occurrence of break down suddenly prior to the inspection.

This result has been considering by Long et al. (2009) in their research. They were using MFOP philosophy and TLOC analysis to optimize the maintenance strategy in order to good balance cost and reliability useful life [7]. Zeng et al. (2015) was studied to predict the probabilistic reliability by using PoF-based models to determine the TTF (time-to-failure). It concluded that the probabilistic reliability ignore the epistemic uncertainty and overestimate the reliability [8]. Other investigation by Noorossana and Laghaie (2015) proposed model of time-based maintenance to optimize the availability of maintenance system. It was assumed that processes of random usage are unrestrained [9].

\section{Conclusion}

This paper describes the determining interval of maintenance using reliability method. The maintenance data was investigated in Finish Mill unit of PT. Bosowa Cement Indonesia, including data of downtime and breakdown. Reliability method was analyzed using Weibull-Plus 4.0 software. It was concluded that the reliability method can determine the interval maintenance between 7 to 17 days.

\section{Acknowledgement}

Authors would like to thank Politeknik Negeri Ujung Pandang and Centre for Manufacturing and Materials for supporting in registration for submission this paper.

\section{References}

[1] CE. Ebeling, An introduction to reliability and maintainability engineering. Long Grove, Waveland Press, 2010.

[2] T. Onisawa, "An application of fuzzy concepts to modeling of reliability analysis," Fuzzy Sets and Systems, vol. 37, no. 3, pp. 267-286, 1990.

[3] B. Cappelle and E. E. Kerre, "Computer assisted reliability analysis: an application of possibilistic reliability theory to a 
subsystem of a nuclear power plant," Fuzzy Sets and Systems, vol. 74, no. 1, pp.103-113, 1995.

[4] K. Y. Cai, Introduction to Fuzzy Reliability. Boston: Kluwer academic publishers, 1996.

[5] C. Cremona and Y. Gao, "The possibilistic reliability theory: theoretical aspects and application," Structural Safety, vol. 19, no. 2, pp. 173-201,1997.

[6] L. V. Utkin and S. V. Gurov, "A general formal approach for fuzzy reliability analysis in the possibility context," Fuzzy Sets and Systems, vol. 83, no. 2, pp. 203-213, 1996.
[7] J. Long, R A. Shenoi, and W. Jiang, "A reliability-centred maintenance strategy based on maintenance-free operating period philosophy and total lifetime operating cost analysis" Proc. IMechE Vol. 223 Part G: J. Aerospace Engineering, 2009

[8] Zeng. Zhiguo, et al. "Measuring reliability during product develonment considering aleatorv and enistemic uncertainty." Reliabilitv and Maintainability Symposium (RAMS), 2015 Annual. IEEE, 2015.

[9] Noorossana, Rassoul, and Kamyar Sabri-Laghaie. "Reliability and maintenance models for a dependent competing-risk svstem with multiple time-scales." Proceedings of the Institution of Mechanical Enoineers. Part O: .Journal of Risk and Reliability (2015): 1748006X14565842. 